\title{
The Effect of Erythropoietin on Ischemic Colitis: An Experimental Rodent Model: Original Article
} \author{
Adas $^{1}$, Hale Ozgun ${ }^{4}$ and Murat Aksoy ${ }^{5}$ \\ ${ }^{1}$ Okmeydani Training and Research Hospital, Department of Surgery \\ ${ }^{2}$ Istanbul Faculty of Medicine, Department of Biochemistry Okmeydani \\ ${ }^{3}$ Training and Research Hospital, Department of Pathology \\ ${ }^{4}$ Istanbul Technical University, Department of Engineering \\ ${ }^{5}$ Istanbul Faculty of Medicine, Department of Vasculary Surgery
}

Oguzhan Karatepe ${ }^{1 *}$, Idris Kurtulus ${ }^{1}$, Orcun Unal ${ }^{1}$, Orhan Yalcin ${ }^{1}$, Ahu Kemik², Gulcin Kamali ${ }^{3}$, Gokhan Adas ${ }^{1}$, Muharrem Battal ${ }^{1}$, Mine

\begin{abstract}
Background: Erythropoietin (Epo), a hormone produced by the kidney that promotes the formation of red blood cells in the bone marrow, is considered anti-inflammatory,anti-apoptotic, angiogenetic and sitoprotective. In this study, high dose erythropoietin is examined on an animal model for ischemic colitis (IC) to detect its possible potential benefits.

Methods: Thirty female Wistar albino rats weighing 250-300 g were randomized into three experimental groups as follows: in Group 1, animals were sham operated $(n=10)$ and received distilled water; in Groups 2 and 3, the rats underwent a standardized surgical procedure to induce IC ( $n=10$ in each group). Group 2 animals served as the controls, receiving only tap water, while Group 3 animals received $3000 \mathrm{lU} / \mathrm{kg}$ eritropoetin as a single high dose. All animals were sacrificed $72 \mathrm{~h}$ after devascularization. Colonic malondialdehyde (MDA) levels, glutathione (GSH), myeloperoxidase (MPO), and caspase 3 activities of the sacrified rats were measured. CD-34 was evaluated by the immunohistochemical examination of the colonic tissue.

Results: Colonic ischemia significantly increased the colonic MDA levels, caspase 3 activity, and TNF alfa in comparison to the control group. Epo treatment was associated with increased GSH levels, decreased MDA, and caspase 3 activity. Histopathological examination revealed that the intestinal mucosal structure was preserved in the Epo treated group. Moreover, treatment with Epo significantly increased CD-34 (stem cell) when compared to the ischemic colitis group.
\end{abstract}

Conclusion: Epo reduced colonic damage in ischemic colitis. The mechanism of the protection associated with Epo was due to its mobilization of the stem cells as well as its anti-apoptotic and anti-inflammatory effects.

Keywords: Erythropoietin; Ischemic colitis; Oxidative damages; Stem cell

\section{Introduction}

Ischemic colitis is an inflammation and injury of the large intestine resulting from inadequate blood supply [1]. Although uncommon in the general population, it occurs with greater frequency in the elderly, and is the most common form of bowel ischemia [1,2]. Causes of the reduced blood flow can include changes in the systemic circulation or local factors such as constriction of blood vessels or a blood clot. Patients with mild to moderate ischemic colitis(IC) are usually treated with IV fluids, analgesia, and bowel rest (that is, no food or water by mouth) until the symptoms resolve. Those with severe ischemia who develop complications such as sepsis, intestinal gangrene, or bowel perforation may require more aggressive interventions such as surgery and intensive care. Despite many researches in literature, we still do not have a time-saving or therapeutic agent $[1,2,3]$.

On the other hand, angiogenesis is a promising new therapeutic strategy for severe ischemia; however, the effects of angiogenic therapies to improve ischemia are not durable or stable. Hypoxia inducible factor-1 (HIF-1), which upregulates both erythropoietin (Epo) and VEGF, is one of the important factors to induce angiogenesis, $[4,5]$. These angiogenic cytokines play an important role in recruitment of bone marrow (BM)-derived cells to ischemic tissue, enhancing endothelial cell proliferation and migration, synthesis of extracellular matrix and resultant angiogenesis. Furthermore, systemic administration of Epo mobilizes endothelial progenitor cells (EPCs) and recruits them to ischemic tissue, where EPCs produce abundant cytokines including VEGF and promote postnatal vasculogenesis [6]. Currently, researchers have focused on the nonhemopoietic effects of erythropoietin and its potential use against tissue ischemia $[4,5,6]$. The aim of the study is to examine the potential benefits of the eritropoetin on an animal model for IC, it is the first time in literature.

\section{Material and Methods}

\section{Animals}

30 famale Wistar-albino rats weighing 250-300 g (Istanbul University, Institute of Experimental Medicine and Research, Turkey) were used in the study. All animals were housed in wire-mesh bottomed cages in 12 hours light/dark cycle. Rats were kept in a room at a constant temperature, $22 \pm 2^{\circ} \mathrm{C}$, and were fed a standard chow diet and water. Rats were randomly allocated to one of three groups containig 10 rats each as follows;

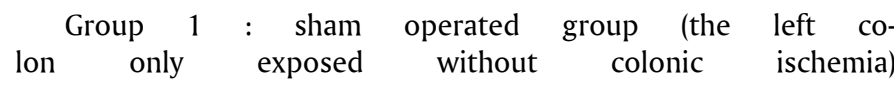

*Corresponding author: Dr. Oguzhan Karatepe, Department of General Surgery, Okmeydanı Training and Research Hospital, Istanbul, 34715, Turkey, Tel: +90 533 54080 70; Fax: +90 21636121 40; E-mail: drkaratepe@yahoo.com

Received November 12, 2010; Accepted December 05, 2010; Published December 20, 2010

Citation: Karatepe O, Kurtulus I, Unal O, Yalcin O, Kemik A, et al. (2010) The Effect of Erythropoietin on Ischemic Colitis: An Experimental Rodent Model: Original Article . J Cytol Histol 1:108. doi:10.4172/2157-7099.1000108

Copyright: (c) 2010 Karatepe O, et al. This is an open-access article distributed under the terms of the Creative Commons Attribution License, which permits unrestricted use, distribution, and reproduction in any medium, provided the original author and source are credited. 
Group 2 : left colonic ischemia

Group 3: left colonic ischemia + Erythropoietin treatment group

\section{Chemicals}

RHuEpo (Eprex, Janson-Cilag) was a generous gift from Santa Farma Ilac Sanayi, Istanbul, Turkey. The compounds, which were used for preparing Krebs solution, were purchased from Merck (Merck KGaA, Darmstadt, Germany).

\section{Surgical procedure}

Anesthesia was introduced by injecting ketamine $\mathrm{HCL}$ at 100 $\mathrm{mg} / \mathrm{kg}$ intra-muscularly (i.m.), and a laparotomy was performed under sterile conditions. Group 2 and 3 animals underwent selective devascularization of a $4-\mathrm{cm}$ segment of descending colon using a modification of the technique described by Griffen and Hagihara [7]. The left colon was only exposed in Group 1 animals (shamoperated) without devascularization. All animals were sacrificed 72 $\mathrm{h}$ after devascularization. Colonic tissue samples were collected for examination.

\section{Histopathological analysis}

Serial sections were taken from ten percent formalin fixed paraffin embedded tissue blocks of intestinal tissues and stained with Hematoxilen \& Eosin (H\&E). Tissue injury in the intestinal mucosa was evaluated using light microscopy according to the criteria described by Chiu et al. [8] and graded from 0 to 5 [8]. The grades are: Grade 0: Normal mucosa; Grade 1: Formation of subepithelial detachments at the tip of the villi with capillary congestion; Grade 2: Subepithelial detachments exerted a moderate amount of upward push on the mucosa epithelium; Grade 3: Large subepithelial detachments exerted a massive amount of upward push on the mucosa epithelium along the villi and few denuded villus tips were observed; Grade 4: The villi were denuded to the level of lamina propria and dilated capillaries; Grade 5: Presence of ulceration, disintegration of lamina propria, and hemorrhage.

\section{Evaluation of oxidative stress}

Postmortem ischemic colonic samples were taken and kept on an ice bath until homogenization. The tissues were homogenized in (20 wt/vol) serum physiologic solution $(\% 0.9 \mathrm{NaCl})$, then centrifuged at $4,000 \mathrm{~g}$ for 15 minutes and upper clear supernatants were used in the assays. All the procedures were performed at $4^{\circ} \mathrm{C}$ throughout the experiments. Protein level of the clear supernatants was studied by Lowry's method. Malondialdehyde (MDA) levels (nmol/mg) and glutation $(\mathrm{GSH})(\mathrm{mIU} / \mathrm{mg})$ enzyme activities were measured in the supernatants. The levels of MDA in tissue samples were determined as an indicator of lipid peroxidation. MDA levels were measured by thiobarbituric acid reactive substances method [9].

\section{Measurement of tissue MPO activity}

The MPO activity was measured to determine the degree of neutrophil accumulation in the tissue samples. The assay was based on a method described by Bradley et al. [10].

Caspase-3 activity: Caspase- 3 activity was measured by quantifying the cleavage of acetyl- Asp-Glu-Val-Asp p- nitroaniline (Ac-DEVD-pNA) with a colorimetric Caspase-3 assay kit (Sigma). Pnitroaniline released by the enzymatic hydrolysis of Ac-DEVD-pNA was calculated from a p-nitroaniline standard curve and the molar absorptivity coefficient of p-NA at $405 \mathrm{~nm}(10500 \mathrm{M}-1 \mathrm{~cm}-1)$. The supernatant obtained by the centrifugation of $10 \%(\mathrm{w} / \mathrm{v})$ tissue homogenate at $15000 \mathrm{x} \mathrm{g}$ for $5 \mathrm{~min}$ at $4^{\circ} \mathrm{C}$ was used as an enzyme source and incubated with and without caspase- 3 inhibitor. Caspase activity was calculated by substracting the absorbance measured in the presence of substrate plus inhibitor from the absorbance observed by incubating with substrate alone for $20 \mathrm{~min}$ at $37^{\circ} \mathrm{C}$. The activity of the enzyme was expressed as pnitroaniline liberated per $\mathrm{mg}$ protein per min. The protein concentration of enzyme source was measured by using bicinchoninic acid [11].

Immunohistochemistry: Immunohistochemical staining was used to locate CD34 expression in colonic tissue. Sections were incubated at $60^{\circ} \mathrm{C}$ overnight, and then deparaffinized in xylene for $30 \mathrm{~min}$. After rehydrating through a graded ethanol series, sections were treated with two percent trypsin at $37^{\circ} \mathrm{C}$ for $15 \mathrm{~min}$. Sections were then incubated in a solution of three percent $\mathrm{H}_{2} \mathrm{O}_{2}$ for $15 \mathrm{~min}$ to inhibit endogenous peroxidase activity. Next, the sections were incubated overnight with anti-eNOS antibody (GeneTex, Inc, San Antonio, TX, USA) and then for another $30 \mathrm{~min}$ with the biotinylated mouse secondary antibody. The bound secondary antibody was then amplified with Vector Elite ABC kit (Vectastain, Vector Laboratories, Burlingame, CA, USA). The antibody-biotin-avidin-peroxidase complexes were visualized using 0.02 percent $D A B$ and nuclei were counterstained with Harris hematoxylin. The sections were finally mounted onto lysine-coated slides. This analysis was performed in at least ten areas per jejunal section, in two sections from each animal at $\times 40$ magnification. The immunolabelling scores were evaluated blindly. Immunolabelling intensity was graded as mild (1), moderate (2), strong (3), and very strong (4).

Statistical analysis: All data were expressed as mean \pm SD. KruskalWallis and ANOVA were used for statistical analysis. When analysis of variance showed a significant difference, the post hoc multiple comparison test was applied to demonstrate the differences. In each test, the data was expressed as the mean value \pm S.D. and $p<0.05$ was accepted as statistically significant.

\section{Results \\ MDA levels}

The MDA content of the sham-operated control animals averaged $61.00 \pm 3.59 \mathrm{nmol} / \mathrm{g}$ tissue, while animals subjected only to ischemia were found to have $139.50 \pm 5.77 \mathrm{nmol} / \mathrm{g}$ tissue $(\mathrm{P}=0.01)$. Treatment with $3000 \mathrm{U} / \mathrm{kg}$ of rHuEpo significantly reduced the intestinal MDA content to the sham-operated control levels. With an average value of $110.66 \pm 4.92 \mathrm{nmol} / \mathrm{g}$ tissue, this group was statistically significant from the ischemic control group $(\mathrm{P}<0.05)$ (Table 1).

\section{MPO activity}

The MPO enzyme activities in the terminal colonic samples from animals subjected to sham operation, ischemic control, and 3000 $\mathrm{U} / \mathrm{kg}$ of rHuEpo treatment averaged (inU/mgtissue) 15.99 \pm 0.92 , $44.35 \pm 1.74$, and $35.97 \pm 1.30$, respectively. The MPO activity of samples from animals pretreated with $3000 \mathrm{U} / \mathrm{kg}$ of rHuEpo was significantly different from that in the ischemic control group $(\mathrm{P}=0.001$ and $\mathrm{P}=0.001$, respectively).

\section{GSH levels}

GSH levels measured in the ischemic control group $(1.34 \pm 0.17$ $\mu \mathrm{mol} / \mathrm{g}$ tissue) decreased approximately $48 \%$ compared to those

\begin{tabular}{|l|l|l|l|l|}
\hline Mean SD & Group 1 & Group 2 & Group 3 & $\mathrm{p}$ \\
\hline MDA & $61.00 \pm 3.59$ & $139.50 \pm 5.77$ & $110.66 \pm 4.92$ & $(\mathrm{P}<0.05)$ \\
\hline MPO & $15.99 \pm 0.92$ & $44.35 \pm 1.74$ & $35.97 \pm 1.30$ & $\mathrm{P}=0.001$ \\
\hline Capasa 3 activity & $0.33 \pm 0.101$ & $.37 \pm 0.10$ & $0.87 \pm 0.09$ & $\mathrm{P}=0.001$ \\
\hline \multicolumn{5}{|c|}{ Table 1: Biochemical results in colonic tissue. }
\end{tabular}


measured in the sham operated group $(4.46 \pm 0.22 \mu \mathrm{mol} / \mathrm{g}$ tissue) $(\mathrm{P}=0.001)$. Pretreatment with rHuEpo at both doses significantly ameliorated the decrease in GSH levels. The mean GSH content for the $3000 \mathrm{U} / \mathrm{kg}$ of rHuEpo-pretreated group was $2.71 \pm 0.22 \mu \mathrm{mol} / \mathrm{g}$ tissue.

\section{Caspase-3 activity}

The caspase- 3 activity of the colon was found to be significantly higher in the Group $2(1.37 \pm 0.10)$ compared to sham group $(0.33 \pm 0.10),(\mathrm{p}<0.001)$. Treatment with grHuEpo $(0.87 \pm 0.09)$ in decreased the caspase- 3 activity when compared to the group 2, $(\mathrm{p}<0.001)$

\section{Histopathological findings}

The most dramatic alterations were observed in the ischemic control group (Group2). Inflammation, mucosal denudation, and edema were clearly detected on some parts of the mucosa and submucosa. Sloughing on some of the surface epithelium was also obvious. The ischemic control group was evaluated as grade 4 . In the sham-operated control group(group1), a normal appearance of the tissues was evident, as demonstrated in Figure 1A; this group was given a grade 0 . Pretreatment with rHuEpo at a $3000 \mathrm{U} / \mathrm{kg}$ dose, however, resulted in moderate mucosal damage, with only minimal focal denudations of the villi epithelium, and this group received a grade 1 (Figure 1B). Table 2 shows the statistical comparison of groups, based on the semi-quantitative grading of the sections. There was a significant difference in the neovascularization between the groups which were given and not given EPO. In the group 3 in which
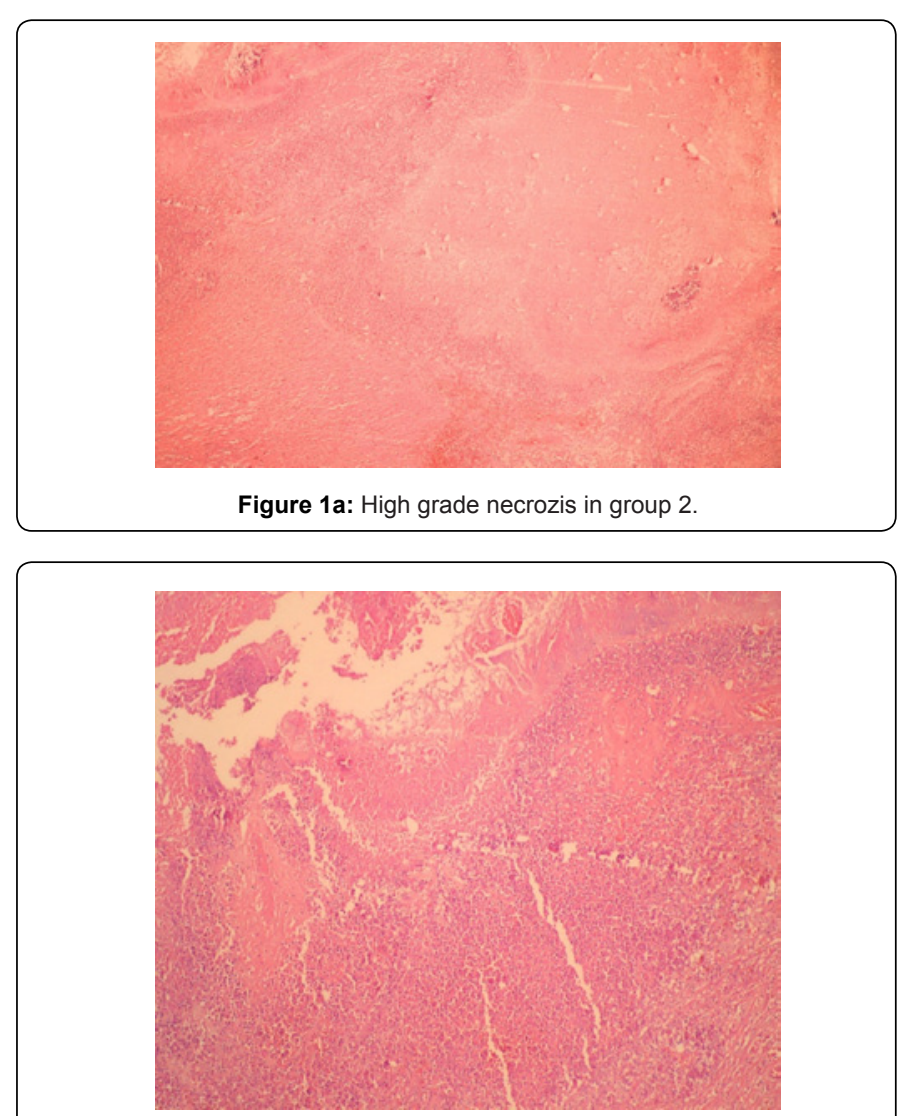

Figure 1b: Pretreatment with rHuEpo at a $3000 \mathrm{U} / \mathrm{kg}$ dose, however, resulted in moderate mucosal damage, with only minimal focal denudations of the villi epithelium, and this group received a grade 1 (Figure 1B).

\begin{tabular}{|l|l|l|l|}
\hline $\begin{array}{l}\text { Histological } \\
\text { Assesment }\end{array}$ & Ephytelization & $\begin{array}{l}\text { Inflammatory } \\
\text { Process }\end{array}$ & Neovascularization \\
\hline Group 1 & 0.3 & 1.3 & 2.5 \\
\hline Group 2 & 0.3 & 2.4 & 0.7 \\
\hline Group 3 & $\begin{array}{l}0.3 \\
(p>0.05)\end{array}$ & $\begin{array}{l}2.2 \\
(p>0.05)\end{array}$ & $\begin{array}{l}1.5 \\
(p=0.001)\end{array}$ \\
\hline
\end{tabular}

Table 2: Histopathological assessment.

EPO was given, neovascularization was observed in an intense way in respect to all the other groups and this difference was significant $(\mathrm{p}=0.001)$.

Immunohistochemistry of CD-34 in the colonic tissue: CD-34 positivity was strongest in the colon of animals in Group 3. Treatment with Epo in addition to ischemic colitis significantly increase the CD34 expression when compared to group $2(\mathrm{p}<0.05)$ (Figure 2A-B).

\section{Discussion}

The result of the present study suggests that oxidative damage, apoptosis, and MPO activity contribute to the development of ischemic colitis which can be assessed by decreased GSH levels and increased MDA levels, caspase- 3 activity and MPO over expression in the colonic tissue. Our results also demonstrate that Epo provides protection against ischemic colonic damage for the first time in the literatures. Epo treatment may be due in part to the suppression of oxidative stress and inflammatory response via the inhibition of leukocyte infiltration

Wound healing in the gastrointestinal system involves related processes such as hemostasis and inflammation, proliferationfibroplasia and maturation and remodeling. Delay or problem in any of these stages results with a delay in healing. There are numerous local and systemic factors that affect ischemic colonic healing. The most important local factor is the perfusion and oxygenation of the site of ischemia. Ischemic colitis results from a temporary blockage of blood flow through arteries that supply the large intestine. Although what causes IC is not clear enough, it is more common among people with heart and blood vessel disease, people who have had surgery on their aorta, or people who have problems with increased blood clotting. In the treatment, it is important to enable blood flow to the ischemic area and to solve the primary pathogenesis before a possible cell damage develops. However, there is no certain well-defined therapy in use today on the cellular basis. Within this context, the data from this novel study demonstrate that Epo conducts antiapoptotic and antioxidative effects, protects the ischemic tissue against further oxidative damage, most probably through an angiogenetic effect.

Apoptosis is known as programmed cell death. Apoptosis is an essential physiological process required for maintenance of tissue homeostasis [12]. One common cellular response to oxidative injury is apoptosis. Apoptosis increases in the gastrointestinal disease such as in IBD, colon and pancreas cancer, acute pancreatitis, radiation enteritis [13]. Although many factors are involved in apoptotic program, caspases have been shown to play a major role in the transduction of apoptotic signals. In the present study, colonic caspase- 3 activity was found to be significantly higher in the group 2 rats when compared to group 1 .

Scientists researched to prevent and minimize the effects of ischemia for many years and for his purpose certain agents have been used in different experimental models (literatur-oguzhan). Recently Epo has become popular and ongoing experiments re worldwide conducted in different body systems to prevent ischemic injury, beyond its well known hematopoietic effects [14]. 


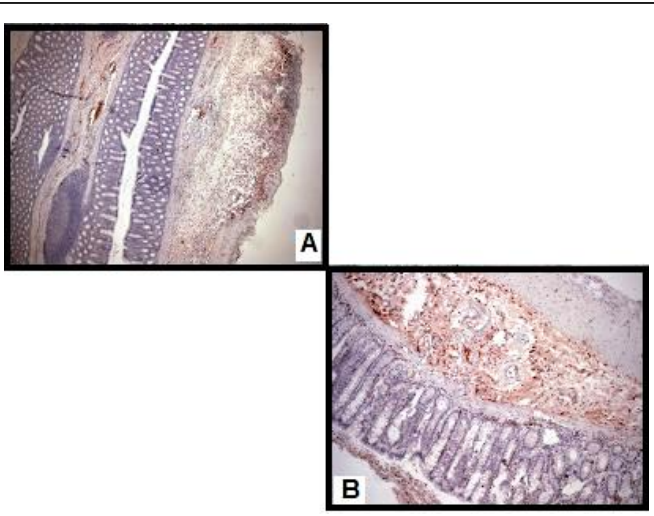

Figure 2ab: CD-34 positivity was strongest in the colon of animals in Group 3

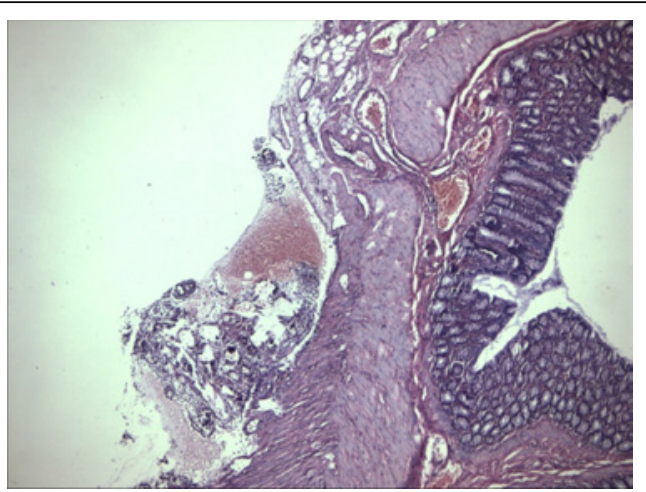

Figure 2c: CD-34 positivity was strongest in the colon of animals in Group 3

Epo is a hypoxia-induced cytokine that stimulates erythropoiesis through the promotion of erythroid precursor cell proliferation and differentiation $[15,16]$. Although, research has focused on the nonhemopoietic effects of erythropoietin against tissue ischemia due to the unexpected observations of erythropoietin receptor expression by various cells, such as endothelial cells, nuronal cells, cardiac myocytes, and vascular smooth muscle cells $[15,16,17,18]$.

Following the preconditioning stimulus, an early period of acute protection is observed and lasts 1 to $2 \mathrm{~h}$. Afterwards, a late period of delayed protection occurs and continues for about 12 to $72 \mathrm{~h} \mathrm{[18]}$. It has been reported that rHuEpo can exert a significant cardioprotective effect when given $24 \mathrm{~h}$ before ischemia [18]. In our study, the doses chosen for the Epo administration was $3000 \mathrm{U}$ per $\mathrm{kg}$ of body weight, which has already been shown to be an effective preconditioning dose regimen in rat models of myocardial and renal $\mathrm{I} / \mathrm{R}$ [19]. The administration time was also within the protective window of Epo. Literature lacks any studies its dose and effects on colonic ischemia. In our study, angiogenesis was remarkable in the Epo group on the 3th postoperative day. Control group consisted of poor capillaries when compared to the Epo group. The speed of neoangiogenesis in the EPO group could suggest the presence of EPO receptors in the endothelial cells. These receptors have previously been found in humans like in rats [19]. It is known that oxygen is critical for ischemic wound healing. The process of angiogenesis, whereby new capillaries are formed from pre-existing blood vessels, is essential for wound healing. At the molecular level of angiogenesis, vascular endothelial growth factor (VEFG) and nitric oxide (NO) are the two key factors that are relevant. According to Jaquet et al. Epo found to have equal angiogenic potential with vascular endothelial growth factor [20]. The molecular mechanisms of angiogenesis and the reflection of it to the healing process are not clearly understood yet; however, we definitely observed new capillary formation in the Epo group.

Many studies have demostrated that erythropoietin has a protective effect on tissue injury associated with ischemia reperfusion injury in many tissues, including brain, retina, cardiac, liver, kidney, lung and intestine [21]. For instance, in neuroprotection afforded by Epo, the modulation of cellular glutathione peroxidase activity was proposed to be a potential underlying mechanism [21]. Moreover, Epo provides the protection of astrocytes from OFRs and can partially compensate for the deficiency of mitochondrial superoxide dismutase (SOD) [22]. Therefore, the improvement of GSH content with rHuEpo may play a key role in preventing exacerbation of tissue damage caused by $\mathrm{I} / \mathrm{R}$. In fact, determining the GSH level can reflect the antioxidative capacity of reperfused tissue. In the present study, when colonic malondialdehyde (MDA) and glutathione (GSH) levels as indicators of oxidative damage were measured, there were significant differences between Epo- treated group and control group $(\mathrm{p}=0.001)$.

Briefly, Epo is believed to serve a manifold role in several tissues with primary target being the protection from ischemia. Our results clearly demonstrate that, according to the histopathological and biochemical parameters, administration of Epo, accelerated the healing of ischemic colitis. These findings may provide insight into potential therapeutic approaches to improve and promote healing of ischemic colitis and to minimize the morbidity and mortality associated with colonic gangrene. We believe the findings of this study should be warrented by large numbered experimental and prospective clinical studies.

\section{References}

1. Sreenarasimhaiah J (2005) Diagnosis and management of ischemic colitis Curr Gastroenterol Rep 7: 421-426.

2. Medina C, Vilaseca J, Videla S, Farba R, Armengol-Miro JR, et al. (2004) Outcome of patients with ischemic colitis: review of fifty-three cases. Dis Colon Rectum 47: 180-184

3. Irkorucu O, Tascilar O, Karadeniz CG, Karakaya K, Emre AU, et al. (2008) The Effect of Sildenafil on an Animal Model for Ischemic Colitis. Dig Dis Sci 53: 1618-1623.

4. Mori S, Sawada T, Okada T, Kubota K (2008) Erythropoietin and its derivative protect the intestine fromsevere ischemia/reperfusion injury in the rat. Surgery 143: 556-565.

5. Rafiee P, Shi Y, Su J, Pritchard Jr KA, Tweddell JS, et al. (2005) Erythropoietin protects the infant heart against ischemia-reperfusion injury by triggering multiple signaling pathways. Basic Res Cardiol 100: 187-197.

6. Silva M, Grillot D, Benito A, Richard C, Nuñez G, et al. (1996) Erythropoietin can promote erythroid progenitor survival by repressing apoptosis through $\mathrm{Bcl}-$ $\mathrm{XL}$ and Bcl-2. Blood 88: 1576-1582.

7. Griffen TS, Hagihara PF (1982) Ischemic colitis in rats. Dis Colon Rectum 25 638-640.

8. Chiu CJ, McArdle AH, Brown RA, Scott HJ, Gurd FN (1970) Intestinal mucosa lesion in low-flow states. I. A morphological, hemodynamic, and metabolic reappraisal. Arch Surg 101: 478- 483

9. Beuge JA, Aust SD (1978) Microsomal lipid peroxidation. Methods Enzymo 52: 302-310.

10. Bradley PP, Priebat DA, Christensen RD, Rothstein G (1982) Measurement of cutaneous inflammation: estimation of neutrophil content with an enzyme marker. J Invest Dermato 178: 206-209.

11. Chang WK, Yang KD, Chuang H, Jan JT, Shaio MF (2002) Glutamine protects activated human $\mathrm{T}$ cells from apoptosis by up-regulating glutathione and $\mathrm{Bcl}-2$ levels. Clin Immunol 104: 151-160. 
Citation: Karatepe O, Kurtulus I, Unal O, Yalcin O, Kemik A, et al. (2010) The Effect of Erythropoietin on Ischemic Colitis: An Experimental Rodent Model: Original Article . J Cytol Histol 1:108. doi:10.4172/2157-7099.1000108

Page 5 of 5

12. Potten CS, Wilson JW, Booth C (1997) Regulation and significance of apoptosis in the stem cells of the gastrointestinal epithelium. Stem Cells 15: 82-93.

13. Jones BA, Gores GJ (1997) Physiology and pathophysiology of apoptosis in epithelial cells of the liver, pancreas, and intestine. Am J Physiol 273: 1174 1188.

14. Furlani D, Klopsch C, Gäbel R, Ugurlucan M, Pittermann E, et al. (2008) Intracardiac erythropoietin injection reveals antiinflammatory potential and improved cardiac functions detected by forced swim test. Transplant Proc 40 : 962-966.

15. Bittorf T, Büchse T, Sasse T, Jaster R, Brock J (2001) Activation of the transcription factor NF-KB by the erythropoietin receptor. Structural requirements and biological significance. Cell Signal 13: 673-681.

16. Masuda S, Nagao M, Sasaki R (1999) Erythropoietic, neurotrophic, and angiogenic functions of erythropoietin and regulation of erythropoietin production. Int J Hematol 70: 1-6.

17. Cai Z, Manalo DJ, Wei G, Rodriguez ER, Fox-Talbot K, et al. (2003) Hearts from rodents exposed to intermittent hypoxia or erythropoietin are protected against ischemia-reperfusion injury. Circulation 108: 79-85

18. Sharples EJ, Patel N, Brown P, Stewart K, Mota-Philipe H, et al. (2004) Erythropoietin protects the kidney against the injury and dysfunction caused by ischemia-reperfusion. J Am Soc Nephrol 15: 2115-2124.

19. Yang CW, Li C, Jung JY, Shin SJ, Choi BS (2003) Preconditioning with erythropoietin protects against subsequent ischemia-reperfusion injury in rat kidney. FASEB J 17: 1754-1755

20. Jaquet K, Krause K, tawakol-Khodai M, Geidel S, Kuck KH (2002) Erythropoietin and VEGF exhibit equal angiogenic potential. Microvasc Res 64: 326-333.

21. Gallucci MT, Lubrano R, Meloni C, Morosetti M, Villahermosa MDS (1999) Red blood cell membrane lipid peroxidation and resistance to erythropoietin therapy in hemodialysis patients. Clin Nephrol 52: 239-245.

22. Genc S, Akhisaroglu M, Kuralay F, Genc K (2002) Erythropoietin restores glutathione peroxidase activity in 1-methyl-4-phenyl-1,2,5,6-tetrahydropyridineinduced neu- rotoxicity in C57BL mice and stimulates murine astroglial glutathione peroxidase production in vitro. Neurosci Lett 321: 73-76. 